\title{
FAKTOR PENGHAMBAT TINGKAT KEDISIPLINAN SISWA DI SMAN 1 BANTAENG
}

\author{
Oleh: Akbar Kurniawan', Andi Agustang2 \\ ${ }^{12}$ Program Studi pendidikan Sosiologi Fakultas Ilmu Sosial dan Hukum \\ Universitas Negeri Makassar \\ Email:_akbarkurniawan139@gmail.com¹,andi.agustang@unm.ac.id
}

\begin{abstract}
Abstrak
Penelitian ini bertujuan untuk mengetahui: Faktor-faktor yang menghambat tingkat kedisiplinan siswa di SMAN 1 Bantaeng. Jenis penelitian ini kualitatif deskriptif dengan penentuan informan melalui teknik purposive sampling dengan kriteria yaitu adalah Kepala Sekolah, Guru da Siswa SMAN 1 Bantaeng dengan jumlah informan 6 orang. Teknik pengumpulan data yaitu observasi, wawancara, dan dokumentasi. Teknik analisis data kualitatif deskriptif melalui tiga tahap yaitu reduksi data, penyajian data, dan penarikan kesimpulan. Teknik pengabshan data menggunakan member check. Hasil penelitian ini menunjukkan bahwa: Faktor-faktor yang menghambat tingkat kedisiplinan siswa di SMAN 1 Bantaeng, yaitu 1) Faktor internal meliputi: (a) Karakter pribadi siswa, dan (b) Rendahnya pemahaman siswa akan pentingnya aturan. 2) faktor eksternal meliputi: (a) Pertemanan, (b) Kemajuan teknologi (game online), (c) Pengaruh gaya (style), dan (d) Lingkungan keluarga dan tempat tinggal.
\end{abstract}

Kata Kunci: Faktor Penghambat, Kedisiplinan siswa.

\section{PENDAHULUAN}

Pendidikan merupakan sebuah proses yang kompleks bukan hnaya sekedar menuntaskan kewajiban melainkan sebuah upaya sistematis dalam rangka pembangunan sumber daya manusia serta masa depan bangsa. Pendidikan tidaklah semata menekankan aspek pengetahuan melainkan juga pada aspek perilaku, Sekolah sebagai salah satu lembaga pendidikan tentunya hadir sebagai sarana belajar dan pembinaan bagi individu sehingga kelak menjadi individu dengan kualitas SDM yang mempuni, sehingga pendidikandirancang sedemikian rupa untuk menjawab tantangan tersebut. Setiap satuan pendidikan tetunya berkiblat pada sebuah regulasi dengan tetap mengedepankan nilai dan norma yang sesuai dengan kepribadian bangsa (Tenri \& Ahmad, 2019). Regulasi atau biasa disebut tata tertib menjadi sebuah hal yang umum dimiliki sekolah, dengan berbegaia bentuk dan tingatan masing-masing. Hadirnya reglasi dan tata tertib ini hakikatnya memberikan sebuah pedoman dalam proses pendidikan di sekolah tersebut, regulasi ini sendiri memiliki kompleksitas yang beragama mulaia dari segi akademik, perilaku hingga fungsional dalam kelembagaan sekolah tersebut (Simanjuntak, 2016).

Hadirnya regulasi ini menjadi sebuah batasan dan kontrol yang diberikan sehingga warga sekolah terutama siswa mampu berperilaku dan berinteraksi sesuai 
dengan nilai dan norma (tata tertib) yang berlaku. Namun tak jarang siswa melakukan pelanggaran terhadap hal tersebut, mulai dari level yang rendah sampai yang tinggi. Perilaku melanggar ini lazim disebut sebagai tindakan indisipliner atau berperilaku tidak dsisplin (Ashadi, 2010).

Secara teoritis aturan dan kedisiplinan siswa dalah sebuah hal yang berjalan beriringan, sehingga keduanya saling bersimultan satu sama lainnya. Sebuah perilaku disiplin lahir dari sebuah aturan dan aturan hadir untuk dipatuhi. Namun realtas yang terjadi perilaku menyimpang dari aturan ini umumnya banyak terjadi, termasuk juga disekolah.

Ragam perilaku tidak disiplin biasa terjadi, misalnya terlambat datang kesekolah, bolos, tidur saat pembelajaran, berseragam tidak sesuai aturan dan lain sebagainya. Beragam pelanggaran tersebut dapat timbul sebagai sebuah pola perilaku yang dipicu oleh banyak hal bisa dari internal siswanya sendiri, seperti memang kepribadiannya malas, suka melanggar dan lain sebagainya (Wirawan, 2011).

Selaian itu hal tersbut juga dapat dipicu oleh hal-hal di luar diri siswa itu sendiri atau sering disebut sebaggai faktor eksternal. Hal ini bisa melipu beraga hal mulaia dari teman bergaul, kurang ketatnya tata tertib itu sendiri dan lain sebagainya. Pada perilaku seperti ini meperngaruhi polabeelajar siswa disekolah serta tercapainya tujuan sebagai manamertinya Sederhananya siswa dengan intensitas belajar tinggi akan memiliki tingkat disiplin yang tinggi terhadap tata tertib sekolah, demikian sebaliknya semakin rendah intensitas belajar siswa semakin rendah pula tingkat disiplin siswa terhadap tata tertib sekolah. Sekolah merupakan lembaga formal sebagai wadah untuk kegiatan pembelajaran. Proses pembelajaran dapat berjalan dengan lancar, jika seluruh siswa mematuhi tata tertib dengan rasa disiplin yang tinggi. Di dalam proses pembelajaran, kedisiplinan diperlukan untuk menunjang keberhasilan siswa. Siswa yang memiliki disiplin dan kepatuhan tinggi akan menunjukkan kesiapannya dalam mengikuti pelajaran di kelas, memperhatikan dan melaksanakan proses pembelajaran dengan lebih baik (Juniati, 2017).

Proses pembelajaran tidak hanya menekankan pada aspek akademis saja, tetapi faktor non akademis juga perlu diperhatikan. Kedisiplinan merupakan aspek non akademis yang perlu diberdayakan secara optimal dalam diri siswa. Karena sifatnya yang abstrak, maka penanaman nilai-nilai kedisiplinan ini harus terintegrasi dalam setiap pembelajaran. Tata tertib disusun oleh sekolah sebagai aturan yang mengikat, sehingga diperlukan kedisiplinan dalam mematuhinya (Aslamiyah, 2020).

Iklim sekolah merupakan lingkungan belajar yang mendorong perilaku positif dan kepribadian sama sehingga menciptakan proses pembelajaran yang optimal. Iklim sekolah yang kondusif dipadu dengan kesadaran yang tinggi untuk mentaati tata tertib sekolah, akan meningkatkan kedisiplinan dan kepatuhan belajar siswa. Implementasinya tidak hanya dilihat dan dirasakan di sekolah, tetapi juga dalam kehidupan siswa di rumah dan lingkungannya. Sederhananya kedisiplinan tumbuh sebagai hasil proses sosialisasi dan internalisasi yang dilakukan siswa terhadap norma 
dan atran sekolah sehingga terbentuk sebuah kesatuan dan pola perilaku yang selaran dengan nilai dan norma dalam sekolah, namun dari hasil observasi awal di SMAN 1 Bantaeng ditemukan bahwa ada saja siswa yang sering melanggar peraturan sekolah, seperti siswa yang tidak lengkap seragamnya,berpenampilan tidak sesuai aturan sekolah, bolos jam pelajaran dan sebagainya. Padahal semestinya seorang siswa harus menaati peraturan yang ada disekolah, sebelum masuk di sekolahpun siswa diharuskan untuk menandatangi pernyataan harus mengikuti peraturan sekolah sebelum memasuki sekolah (Sumardianta \& Sarasvati, 2016).

Faktor yang mendasari siswa sering melanggar peraturan biasanya karena guru yang apatis tidak menindak lanjuti siswa yang melanggar, keluarga yang tidak perhatian kepada anak, atau dari dalam diri anak yang memang tidak sadar peraturan. Perlu dicari tahu alasan seorang siswa sering melanggar peraturan sekolah.

\section{METODE PENELITIAN}

Penelitian ini menggunakan penelitian kualitatif dengan pendekatan deskriptif. "Penelitian kualitatif deksriptif adalah hasil eksporasi subjek penelitian atau para partisipan melalui pengamatan dengan semua variannya, dan wawancara mendalam serta dideskripsikan dalam catatan kualitatif yang terdiri dari catatan lapangan, catatan wawancara, catatan pribadi, catatan metodologis, dan catatan teoritis". Sedangkan Penelitian kualitatif itu sendiri adalah penelitian yang menggunakan metode penalaran induktif dan sangat percaya bahwa terdapat banyak perspektif yang akan diungkapkan, penelitian kualtiatif berfokus pada perasaan dan persepsi partisipan". Didalam prosesnya terdapat upaya mendeskripsikan, mencatat, analisis dan menginterpretasikan kondisi- kondisi yang sekarang ini terjadi atau ada. dengan kata lain penelitian deskriptif bertujuan untuk memperoleh kaitan antara variabel-variabel yang ada. Lokasi penelitian ini adalah di SMAN 1 Bantaeng, Provinsi Sulawesi Selatan. Adapun tahapan dalam penelitian ini yaitu: Tahap Pra Penelitian, Tahap Penelitian, dan tahap akhir. Penelitian ini menggunakan 2 sumber data yaitu sumber data primer dan sekunder.

Pengabsahan data atau validitas data ini diterapkan dalam rangka membuktikan kebenaran temuan hasil penelitian dengan kenyataan dilapangan. Teknikpengabsahan data yang digunakanuntukmengujikredibilitas data dalam penelitian inia dalah member check. Member check dilakukan untuk mengambil temuan kembali pada partisipan dan menanyakan pada mereka baik lisan maupun tertulis tentang keakuratan hasil penelitian. data yang diperoleh dilapangan kemudian diolah secara deskriptif kualitatif dengan melalui tiga tahap yaitu: Reduksi Data, Penyajian Data, Penarikan Kesimpulan.

\section{PEMBAHASAN}

Berdasarkan hasil penelitian yang dilakukan penulis menemukan beberapa bentuk penghambat tingkat kedisiplinan siswa di SMAN 1 Bantaeng, penulis dapat 
mengklasifikasikan menjadi dua aspek yang menghambat kedisplinan siswa disekolah yaitu faktor internal dan faktor eksternal. Faktor internal merupakan akumulasi beberapa aspek yang menghambat perilaku disiplin yang berasal dari dalam diri siswa itu sendiri atau bsa disebut faltor dari dalam siswa it sendiri. Faktor internal ini sendiri menjadi sebuah hal paling dasar dalam membentuk kedisplinan, dimana ini menyangkut pola pikir, mindset, sikap dan perilaku siswa itu sendiri. sedangkan Faktor kedua yang menyebabkan rendahnya kedisplian siswa adalah faktor yang berasal dari luar individu atau siswa. Faktor ini disebut faktor eksternal, hal ini meliputi beberapa aspek seperti petemanan, kemajuan teknologi (game online), pengaruh lingkungan tempat keluarga dan tinggal.

Berdasarkan hasil penelitian di atas dapat dikatakan bentuk perilaku Perilaku tdak displin siswa adalah sebuah hal yang timbul akibat berbagai faktor yaitu sebagai berikut: Faktor internal ini sendiri meliputi beberapa aspek yang berasal dari dalam individu itu sendiri, hal ini tentunya menjadi sebuah aspek menyeluruh sebagai sebuah hal yang mempengaruhi perilaku indisipliner siswa yaitu;

Pertama adalah Karakter Pribadi Siswa (Karakter Malas). Faktor ini adalah yang paling dasar dimana hal tersebut melakat dalam diri individu itu sendiri. Karakter malas menjadi sebuah enghambat paling besar bagi individu dalam memahami dan mematuhi peraturan atau bersikap disiplin (Awaru, 2017). Karakter pribadi siswa ini tentunya menjadi hal yang perting dalam membentuk kedisplinan siswa itu sendiri. Sebagai sebuah hal dasar dalam diri karakter menjadi sebuah cerminan diri dalam menanggapi berbagai rasangan dari luar termasuk peraturan dan regulasi itu sendiri. Perlu dipahami sebuah aturan ada untuk mendisiplinka diri dn sebuah kedisplinan adalah keselarasan perilaku dengan aturan itu sendiri. Faktor ini merupakan hal yang berasal dari luar individu itu sendiri, dimana faktor ini meliputi banyak aspek, mulai dari pertemanan, perubahan dan kemajuan tenologi serta lain sebagainya. Berdasarkan hasil waancara pada di atas, faktor ekternal yang menyebabkan rendahnya kedisplinan siswa meliputi,

Pertama adalah faktor pertemanan. Pertemanan ini sendiri merupakan sebuah bentuk relations atau hubungan dalam bentk sebuah kelompok, biasanya kelompok ini memiliki kedekatan dan keakraban yang kuat dengan individu (Ulfia, 2018). Pada beberapa penjelasan dikatakan bahwa pertemana adalah kelompok yang terbentuk bisa karena persamaan usia, kedekatan tempat tinggal dan lain sebagainya

Kedua adalah kemajuan teknologi, sebagai sebuah perubahan teknologi hador dengan berbaga manfaat dan inovasi yang sangat mmembantu manusia, namun tak dapat dipungkiri bahwa pada beberapa hal membawa pngarah negatif pula bagi masyarakat, salah satunya dengan kehadiran game online (Henry, 2013). Pada hakikatnya game online ini sebagai sebuah alternatif hiburan bagi masyaraat dalam menghilangkan keenatadari suntuknya aktivtas sehari-hari, termasuk bagi siswa. Namun terkadang game online ini juga memberikan efek negatif bagi siswa, dimana 
game online ini enyita anyak waktu siswa bukan hanya waktu belajar bahkan waktu istirahat siswa itu sendiri, dan pada akhirnya meninmbulkan berbagai implikasi berupa kesehatan, sosial, dan ketidaksiplinan siswa, baik itu disiplin belajar, serta kehadiran disekolah.

Hal ini sesuai dengan pendapat (Henry, 2013) (Kadarisman \& Suryanto, 2015), menyatakan bahwa dampak negatif game online di kalangan pelajar yaitu: a). Sering bolos sekolah supaya bisa bermain game online di rental game ataupun warnet, artinya pelajar yang kecanduan game online menghalalkan berbagai cara agar bisa bermain game online tanpa memperdulikan jam belajar aktif di sekolah. Hal ini terbukti berdampak pada prestasi di sekolah yaitu rangking kelas yang rendah. b). Penggunaan uang jajan yang tidak tepat sebagaimana mestinya, uang jajan yang diberikan oleh orang tua sering dihabiskan untuk membeli voucher Game Online dan membayar rental komputer di warnet c). Jarang berolahraga dalam setiap minggu, meskipun terdapat mata pelajaran olahraga di sekolah hal ini dirasa belum cukup bagi kondisi fisik pelajar. d) Dampak negatif yang paling dirasakan dari bermain game online yaitu boros terhadap uang, karena dihabiskan untuk bermain game online. Biaya seperti pembelian voucher game online, biaya penyewaan komputer warnet (billing), makan dan minum selama di warnet, dan biaya lainnya membuat uang jajan yang diberikan (Parti, 2019).

Faktor ketiga adalah pengaruh gaya (style) hal ini tentunya tidak bisa kita lepaskan begitu saja sealain faktor di atas, gaya menjadi sebuah hal yang sering diperhatikan oleh sebagai besar orang, tak terkecuali oleh siswa itu sendiri, hari ini mampu kita amati bahwa tren gaya dan fashion menajdi sebuah hal banyak di jadikan alasan oleh siswa untuk bersikap tidak patuh pada aturan misalya, gaya celana pensil sehingga ketika disekolah diharuskan memakai celana yang tidak seprti itu gaya ia akan cenderung meonalak hal seperti ini yang biasanya menimbulkan pelanggaran dikalangan siswa (Kurniawan, 2018). Pengaruh dari luar ini memang sangat berimbas bagi pelaksanaan tata tertib sekolah, tak jarang kita enjumpai perilaku siswa yang tidak displin pada hal ini.

Faktor yang kemempat adalah Lingkungan keluarga dan tempat tinggal. Lingkungan merupakan sesuatu yang mengelilingi individu di dalam hidupnya, baik dalam bentuk lingkungan fisik seperti orangtua, rumah, kawan bermain, dan masyarakat sekitar maupun dalam bentuk lingkungan psikologis seperti perasaanperasaan yang dialami, cita- cita, persoalan-persoalan yang dihadapi dan sebagainya. Hal tersebut tentunya juga berimbas pada kedisplinan siswa itu sendiri (Apriyadi, 2018). Dimana kedisplinan merupakan sikap patuh terhadap aturan, dimana hal ini bisa bermula dari keluarga dan lingkungan sekitar, apa bila pada keluarga dan lingkungan tempat tinggal kebiasan untuk hidup disiplin tidak dibiasakan maka, akan terbawah kesekolah dan didalam kelas. Hal ini sesuai dengan pandangan (Sofiati, 2012) bahwa "pertumbuhan kepribadian seseorang biasanya dipengaruhi oleh faktor lingkungan keluarga, lingkungan pergaulan, lingkungan masyarakat, dan lingkungan 
sekolah. Disiplin yang diterapkan di masing-masing lingkungan tersebut memberi dampak bagi pertumbuhan kepribadian yang baik".

\section{PENUTUP}

Berdasarkan hasil penelitian yang dilakukan oleh penulis di SMAN 1 Bantaeng, penulis dapat menyimpulkan bahwa Faktor-faktor yang menghambat tingkat kedisiplinan siswa di SMAN 1 Bantaeng, yaitu sebagai berikut: 1) Faktor internal yaitu faktor dari dalam siswa itu sendiri meliputi karakter pribadi siswa dan rendahnya pemahaman siswa akan pentingnya aturan 2). Faktor eksternal yaitu faktor yang berasal dari luar individu, meliputi pertama Pengaruh Pertemanan, kedua kemajuan teknologi (game online), ketiga Pengaruh gaya (Style), dan keempat Lingkungan keluarga dan tempat tinggal. Berdasarkan kesimpulan di atas, adapun saran dari penelitian ini yaitu sebagai berikut: 1). Bagi sekolah agar meningkatkan upaya dengan melakukan kebjakan dan program peningkatan kediplinan bagi siswa. 2). Bagi rang tua agar proaktf melakukan sosialisasi dan edukasi untuk meningkatkan kediplinan anak (siswa).

\section{DAFTAR PUSTAKA}

Apriyadi, N. (2018). IMPLEMENTASI PEMBELAJARAN PENDIDIKAN AGAMA ISLAM DALAM MEMBENTUK KARAKTER ISLAMI SISWA SD NEGERI 45 KOTA $B E N G K U L U$. IAIN BENGKULU.

Ashadi, A. K. (2010). Pengaruh Motivasi Kerja Dan Disiplin Kerja Terhadap Kinerja Karyawan Bagian Produksi I Pada Perusahaan Daerah Air Minum (PDAM) Tirta Moedal Kota Semarang. Universitas Negeri Semarang.

Aslamiyah, S. S. (2020). Implementasi Tata Tertib Sekolah Dalam Penanaman Budaya Disiplin Siswa. TA'LIM: Jurnal Studi Pendidikan Islam, 3(2), 183-194.

Awaru, A. O. T. (2017). Membangun Karakter Bangsa Melalui Pendidikan Berbasis Multikultural Di Sekolah. Prosiding Seminar Nasional Himpunan Sarjana IlmuIlmu Sosial, 2, 221-230.

Henry, S. (2013). Cerdas Dengan Games. Gramedia Pustaka Utama.

Juniati, E. (2017). Peningkatkan hasil belajar matematika melalui metode drill dan diskusi kelompok pada siswa kelas VI SD. Scholaria: Jurnal Pendidikan Dan Kebudayaan, 7(3), 283-291.

Kadarisman, Y., \& Suryanto, R. N. (2015). Dampak Positif dan Negatif Permainan Game Online Dikalangan Pelajar. Riau University.

Kurniawan, W. A. (2018). Budaya tertib siswa di sekolah. CV Jejak (Jejak Publisher).

Parti, N. J. (2019). KEEFEKTIFAN AGGRESSION REPLACEMENT TRAINING DAN KONSELING MOTIVATIONAL INTERVIEWING UNTUK MEREDUKSI AGRESIVITAS PADA SISWA DENGAN KECENDERUNGAN GAME ONLINE DI SMA NEGERI 1 TOBOALI. Universitas Negeri Semarang.

Simanjuntak, J. (2016). KOMPLEKSITAS MANAJEMEN PERGURUAN TINGGI. 
Sofiati, I. (2012). KARAKTERISTIK OUTGOING LONGWAVE RADIATION (OLR) BERDASARKAN EMPIRICAL ORTHOGONAL FUNCTION (EOF) DAN KAITANNYA DENGAN CURAH HUJAN DI WILAYAH INDONESIA [CHARACTERISTICS OF OUTGOING LONGWAVE RADIATION (OLR) BASED ON EMPIRICAL ORTHOGONAL FUNCTION (EOF) AND TH. Jurnal Sains Dirgantara, $10(1)$.

Sumardianta, J., \& Sarasvati, D. P. (2016). Mendidik Pemenang Bukan Pecundang. Bentang Pustaka.

Tenri, A. O., \& Ahmad, M. R. S. (2019). UPAYA GURU DALAM MENGATASI KENAKALAN SISWA DI SMAS MUHAMMADIYAH BENTENG KABUPATEN KEPULAUAN SELAYAR. Jurnal Sosialisasi: Jurnal Hasil Pemikiran, Penelitian Dan Pengembangan Keilmuan Sosiologi Pendidikan, 25-30.

Ulfia, E. (2018). PENGARUH KONSELING KELOMPOK DENGAN MENGGUNAKAN PENDEKATAN REALITAS TERHADAP MINAT BELAJAR PESERTA DIDIK KELAS VII MTS HASANUDDIN KUPANG TEBA TELUK BETUNG TAHUN AJARAN 2017/2018. UIN Raden Intan Lampung.

Wirawan, C. (2011). Faktor-faktor yang melatarbelakangi perilaku destruktif pada remaja pelaku balap liar. University of Muhammadiyah Malang. 